\title{
Erratum: Electric field of a 2D elliptical charge distribution inside a cylindrical conductor [Phys. Rev. ST Accel. Beams 10, 081001 (2007)]
}

\author{
M. A. Furman \\ (Received 31 August 2007; published 11 September 2007)
}

DOI: 10.1103/PhysRevSTAB.10.099901

PACS numbers: 41.20.Cv, 99.10.Cd

The numerator inside the integral in Eq. (3) of Ref. [1] should be $\mathbf{x}-\mathbf{x}^{\prime}$ instead of $\mathbf{x}^{\prime}-\mathbf{x}$. The results and conclusions of the article are not affected by this misprint.

[1] M. A. Furman, Phys. Rev. ST Accel. Beams 10, 081001 (2007). 